\title{
Assessing Problematic Substance Use in HIV Care: Which Questions Elicit Accurate Patient Disclosures?
}

\author{
Wynne Callon, $B A^{7}$, Mary Catherine Beach, $M D, M P H^{7}$, Somnath Saha, $M D, M P H^{2,3}$, \\ Geetanjali Chander, MD, MPH' , Ira B. Wilson, MD'4, Michael Barton Laws, PhD', Victoria Sharp, MD" \\ Jonathan Cohn, $\mathrm{MD}^{6}$, Richard Moore, $M D, M H S^{7}$, and P. Todd Korthuis, $M D, M P H^{3}$ \\ 'Johns Hopkins University School of Medicine, Baltimore, MD, USA; ${ }^{2}$ Portland VA Medical Center, Portland, OR, USA; ${ }^{3}$ Department of Medicine, \\ Oregon Health Sciences University, Portland, OR, USA; ${ }^{4}$ Department of Health Services, Policy \& Practice, Brown University School of Public Health, \\ Providence, RI, USA; ${ }^{5}$ Saint-Lukes Roosevelt, New York, NY, USA; ${ }^{6}$ Department of Medicine, Wayne State University, Detroit, MI, USA.
}

\begin{abstract}
BACKGROUND: Substance use is associated with higher rates of antiretroviral non-adherence and poor HIV outcomes. This study examined how HIV care providers assess substance use, and which questions elicit accurate patient disclosures.
\end{abstract}

METHODS: We conducted a conversation analysis of audio-recorded encounters between 56 providers and 162 patients living with HIV (PLWH) reporting active substance use in post-encounter interviews (cocaine or heroin use in the past 30 days, $>4$ days intoxicated in past 30 days, or AUDIT score $\geq 8$ ). We assessed the frequency of substance use discussion, characterized the types of questions used by providers, and determined the frequency of accurate patient disclosure by question type.

RESULTS: In 55 reports of active substance use, providers already knew about the use $(n=16)$ or patients disclosed unprompted $n=39$ ). Among the remaining 155 instances of substance use in which providers had the opportunity to elicit disclosure, 78 reports (50\%) of substance use were not discussed. Of the remaining 77 reports in which the provider asked about substance use, $55(71 \%)$ patients disclosed and $22(29 \%)$ did not disclose. Questions were classified as: open-ended $(n=18$, "How's the drinking going?"); normalizing ( $n=14$, "When was the last time you used?"); closed-ended ( $n=36$, "Have you used any cocaine?"); leading towards non-use ( $n=9$, "Have you been clean?"). Accurate disclosure followed $100 \%$ of open-ended and normalizing questions, $58 \%$ of closed-ended questions, and $22 \%$ of leading questions. After adjusting for drug type, closed-ended questions were $41 \%$ less likely ( $p<0.001)$, and 'leading' questions $78 \%$ less likely $(p=0.016)$ than broad and normalizing questions to elicit disclosures.

CONCLUSION: Providers in this sample missed almost half of the opportunities to identify and discuss substance use with PLWH. Providers can increase the probability of patient disclosure by using open-ended or normalizing questions that ask about the "last time" that the patient used drugs or alcohol.

KEY WORDS: patient-provider communication; HIV/AIDS; substance use.

Received November 30, 2015

Revised March 8, 2016

Accepted April 27, 2016

Published online May 19, 2016
J Gen Intern Med 31(10):1141-7

DOI: $10.1007 / \mathrm{s} 11606-016-3733-\mathrm{Z}$

๑) Society of General Internal Medicine 2016

\section{INTRODUCTION}

Patients using alcohol and illicit drugs have higher rates of antiretroviral therapy (ART) non-adherence, increased risk of acquiring opportunistic infections, and accelerated disease course. $^{1-11}$ Alcohol, cocaine, and heroin use have all been shown to significantly increase ART non-adherence in patients living with HIV (PLWH). ${ }^{12-14}$ A meta-analysis of the association between alcohol use and ART adherence found that alcohol use is associated with a 40-50\% decrease in ART adherence. ${ }^{11}$ While even "light" alcohol use (less than once a week) is associated with increased viral loads, there is a dosedependent relationship between alcohol use and nonadherence. ${ }^{4,11}$ Similarly, another study found that only $27 \%$ of cocaine users were adherent to their ART regimen. ${ }^{13}$

In a nationally representative survey of PLWH, $18 \%$ of patients reported heavy drinking, $40 \%$ reported illicit drug use other than marijuana, and $12 \%$ screened positive for drug dependence. ${ }^{15}$ Thus, it is critical for HIV care providers to screen for substance use in order to counsel patients and direct them toward treatment. In addition, providers may need to know about concurrent substance use with ART to avoid drug interactions. ${ }^{16,17}$ Importantly, cessation of both alcohol and illicit drug use is associated with rapid improvement in ART adherence, viral load, and CD4 counts, and decreased risk of opportunistic infections, suggesting that provider substance use counseling may have important therapeutic implications. $^{5,7}$ Despite this, providers often fail to elicit information about substance use, both in general outpatient settings and in HIV care. ${ }^{18-21}$ A study of 951 PLWH found that while $71 \%$ reported current or prior illicit drug abuse, only $46 \%$ reported discussing substance use issues with their HIV providers. ${ }^{21}$

To our knowledge, no previous studies have directly analyzed patient-provider dialogue regarding substance use in HIV care. A study in non-HIV patients of audio-recorded conversations between 47 patients with problematic alcohol use and their providers found that providers seemed 
uncomfortable when talking about alcohol, engaged in little follow-up to disclosures, and tended to give tentative advice. ${ }^{22}$ Similarly, a study in New Zealand that analyzed the dialogue between 171 patients and their providers found that discussion of alcohol or drugs (including tobacco) occurred in less than $25 \%$ of visits. ${ }^{20}$ Neither of these studies assessed how clinicians ask about substance use.

To address this gap, this study assesses audio-recorded dialogues between PLWH and their providers regarding alcohol, cocaine, and heroin use. We determined the frequency with which providers ask about substance use, explored the question types that providers use, and assessed the likelihood that each question type elicited accurate patient disclosures of substance use. Our overall goal is to provide guidance to HIV providers when assessing substance use in the clinical interview.

\section{METHODS}

\section{Study Design, Subjects, and Settings}

The data for this study is derived from the three phases of the Enhancing Communication and HIV Outcomes (ECHO) Study. Phase 1 (ECHO1) occurred in 2007-2008 in Baltimore, New York, Portland, and Detroit. Phase 2 (ECHO 2) took place in 2008 in New York, Portland, and Detroit. Phase 3 (ECHO 3) was in 2011 in Baltimore. Providers were physicians, nurse practitioners, and physician assistants, and all were experienced HIV primary care providers. Patients were age 18 or older, English-speaking, and had at least one prior visit with their provider. The three phases included a total of 83 providers and 850 PLWH. All study procedures were institutional review board (IRB) approved at all sites, and all patients and providers provided written informed consent.

In all three phases, routine visits between patients and providers were audio-recorded and transcribed verbatim by a professional transcription company. Research assistants conducted post-encounter interviews with each patient, using questionnaires that included detailed questions about patients' use of cocaine, heroin, and alcohol in the past 30 days. Additional details about the ECHO study are available in previous publications. $^{23-28}$

\section{Study Sample}

All three phases of the ECHO Study used the Addiction Severity Index, Lite version (ASI-lite) ${ }^{29,30}$ in post-encounter patient interviews to characterize current and past substance. From the three phases, we selected transcripts of all patients who disclosed cocaine or heroin use in the past 30 days in post-encounter interviews. To identify problematic alcohol use, we selected transcripts of patients who reported being intoxicated on five or more occasions in the past 30 days (on the ASI-lite ${ }^{30}$ ) or had an Alcohol Use Disorders Identification Test (AUDIT) score of 8 or more. ${ }^{31}$ AUDIT scores were only available in the third phase of the ECHO study.

\section{Conversation Analysis of Dialogue}

One author (WC) read each transcript in its entirety and identified all dialogue related to substance use. Because some patients reported use of more than one substance, we considered each report of substance use separately within the analysis. Within the dialogue, we determined if each report of substance use was discussed, including how the topic was raised. We then abstracted all provider questions regarding substance use and indicated whether the questions elicited an accurate disclosure of use of the substance(s) that the patient had reported in the post-encounter interview.

Providers' questions were analyzed using the principles of conversation analysis: categories were not pre-determined, but instead generated inductively and modified continuously throughout the analytic process (MCB and WC). ${ }^{32,33}$ After we determined the final set of question categories through this process, one investigator (WC) coded all questions into one of the categories. A second investigator (MCB) double coded $20 \%$ of the questions to assess coding reliability, with a Kappa value of 0.91 .

\section{Quantitative Analysis}

After categorizing the questions, we determined the frequency of each question category and used a negative binomial regression to calculate the unadjusted and adjusted relative risks of patient disclosure following each question type, adjusting for substance type (alcohol, heroin or cocaine). Separately, we calculated the rates of no disclosure, full disclosure, and some disclosure (disclosed at least one, but not all, substances for patients who reported using multiple substances). Additionally, we used a logistic regression to evaluate if substance use frequency predicted the probability of provider questioning and/or the probability of patient disclosure. All data analysis was conducted using Stata/SE version 10.0 (College Station, Texas).

\section{RESULTS}

\section{Provider and Patient Characteristics}

Of the 162 patients reporting recent drug and/or alcohol use, 54 were using only alcohol, 57 only cocaine, 10 only heroin, and 41 were using more than one substance. Characteristics of patients and providers are presented in Table 1.

\section{Dialogue Characteristics}

This study included 210 reports of substance use among 162 patients. The distribution of substance use reports is illustrated in Fig. 1. Of note, the 16 cases in which the provider "already knew" about the substance use refer to instances in which the patient had recently been in the Emergency Department due to a substance use-related complaint or because the purpose of the visit was to determine a plan for substance use treatment. 
Table 1. Provider and Patient Samples*

\begin{tabular}{ll}
\hline \hline Provider Characteristics & $\mathbf{N}=\mathbf{5 6}$ \\
\hline Female, $n$ (\%) & $30(54 \%)$ \\
Age, range (mean) & $30-63(44)$ \\
Race, $n$ (\%) & $37(68 \%)$ \\
White & $5(9 \%)$ \\
Black & $3(6 \%)$ \\
Latino & $9(17 \%)$ \\
Other & $36(65 \%)$ \\
Health profession, $n(\%)$ & $11(20 \%)$ \\
Physician & $8(15 \%)$ \\
Nurse practitioner & $\mathrm{N}=162$ \\
Physician assistant & $26-66(47)$ \\
Patient Characteristics & $68(42 \%)$ \\
Age, range (mean) & \\
Female, $n$ (\%) & $26(16 \%)$ \\
Race, $n$ (\%) & $125(78 \%)$ \\
White & $9(6 \%)$ \\
Black & \\
Other & $69(43 \%)$ \\
Education, $n$ (\%) & \\
Less than high school & \\
Substance use & $41(25 \%)$ \\
More than one & $54(33 \%)$ \\
Only alcohol & $57(35 \%)$ \\
Only cocaine & $10(6 \%)$ \\
Only heroin &
\end{tabular}

* Numbers do not add to total due to missing data

When all means of acquiring knowledge about substance use were combined (unprompted patient disclosure, provider already knew, elicited disclosure with a question), providers were aware of 110 instances (52\%) of substance use by the end of the visit, but remained apparently unaware of 100 instances (48 \%) (Table 2).

\section{Poly-Substance Use}

Table 3 shows the distribution of the 41 patients who were using more than one substance. Providers fully elicited disclosure of all substance use in only $29 \%$ of these encounters. In encounters where providers elicited disclosure of some, but not all, substance use, disclosure of cocaine tended to be higher than that of alcohol and heroin. Among patients using cocaine and another substance, cocaine was disclosed in 23 of 36 cases $(64 \%)$. Among patients using alcohol and another substance, alcohol was disclosed in 11 of 25 instances (44\%). Finally, among those using heroin and another substance, heroin was disclosed in 11 of 28 cases (39\%). These differences in disclosure rates were largely due to differences in rates of providers asking about each substance. Providers did not ask about cocaine use in eight of 36 instances (22\%), did not ask about alcohol use in 12 of 25 instances (48\%), and did not ask about heroin in 13 of 28 instances (46\%).

\section{Question Types}

We identified four categories of questions through our conversation analysis: open-ended, normalizing, closed-ended, and leading (toward non-use). Examples of each are presented in Table 4.

1. Open-ended $(n=18)$ : questions that invite the patient to elaborate in their response and cannot be answered with just one word.

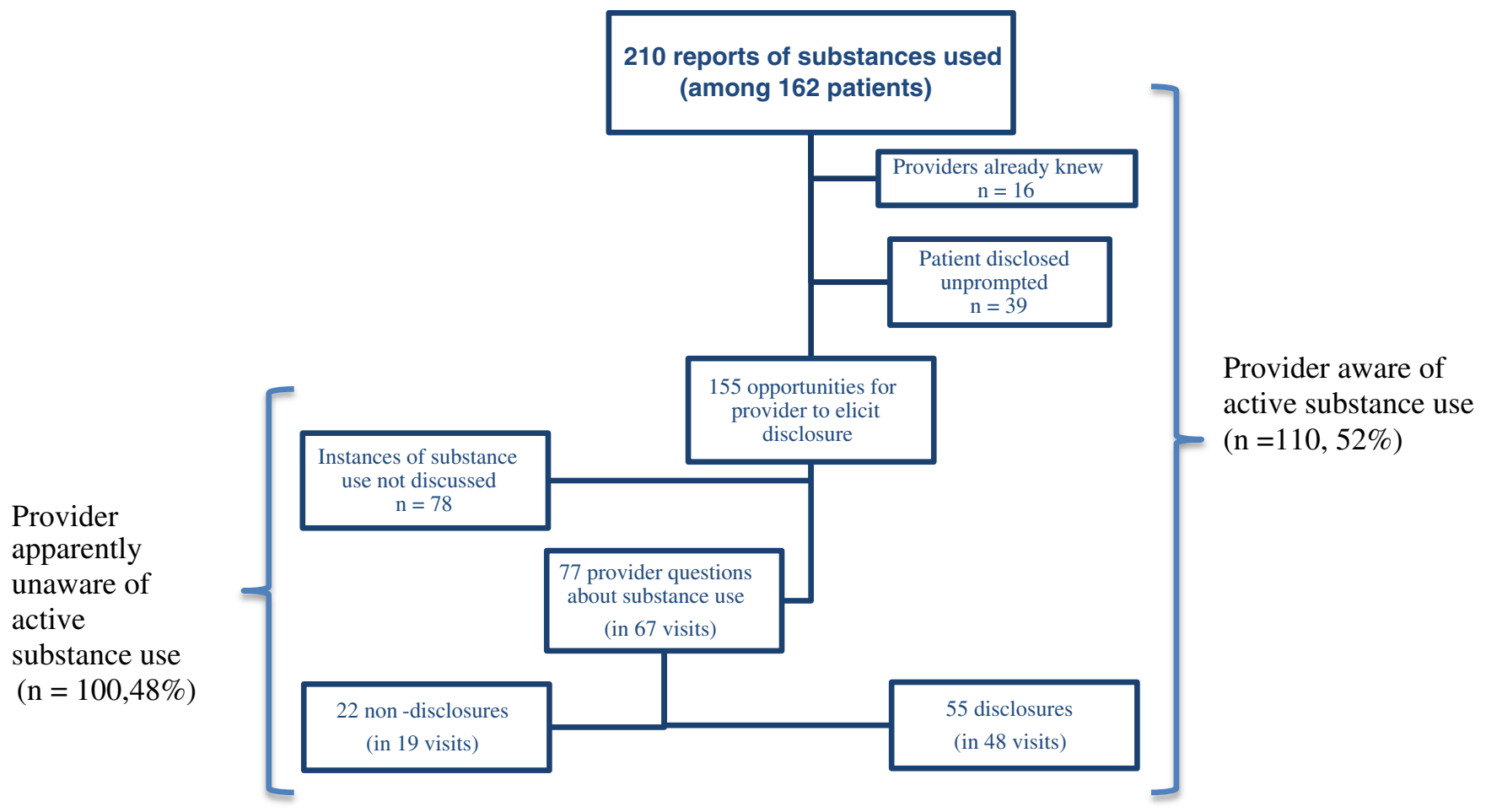

Figure 1. Characteristics of dialogue. 
Table 2. Reports of Substance Use and Disclosure by Substance Type

\begin{tabular}{lll}
\hline \hline & Number of reports $^{\mathbf{a}}$ & Any discussion in visit \\
\hline Alcohol & 78 & $39(50 \%)$ \\
Cocaine & 93 & $54(58 \%)$ \\
Heroin & 39 & $17(44 \%)$ \\
Total & 210 & $110(52 \%)$ \\
\hline
\end{tabular}

${ }^{a}$ Patient reports of substance use in post-encounter survey by research assistant

${ }^{b}$ Includes all instances in which providers were aware of substance use (provider knew prior to visit, unprompted disclosure, disclosure following provider question)

2. Normalizing $(n=14)$ : questions asking specifically about the last time that the patient used alcohol or drugs. The wording of these questions was all very similar, using the phrase "when was the last time..."

3. Closed-ended $(n=36)$ : closed-ended, positively framed questions (contrast with 'leading' below) that either specifically named the drug of interest or more generally referred to drugs without using specific names.

4. Leading towards non-use $(n=9)$ : questions that were negatively framed ("not using") or used phrases such as "staying clean," leading the patient toward nondisclosure of substance use.

\section{Characteristics of Questions and Disclosure of Substance Use}

Overall, 55 of the 77 questions ( $71 \%$ ) elicited disclosures of substance use. Rates of disclosure by question type were $100 \%$ for both open-ended and normalizing questions, $58 \%$ for closed-ended questions, and $22 \%$ for leading questions (Table 4). After adjusting for substance type, closed-ended questions were $40 \%$ less likely $(p<0.001)$, and 'leading' questions $78 \%$ less likely $(p=0.016)$ than open-ended or normalizing questions to elicit an accurate disclosure. There was no significant difference in disclosure rates between the three substance types (Table 5).

Table 3. Poly-Substance Users $(N=41)$

\begin{tabular}{lllll}
\hline \hline & Patients & $\begin{array}{l}\text { Discussion } \\
\text { of none }\end{array}$ & $\begin{array}{l}\text { Discussion } \\
\text { of some* }\end{array}$ & $\begin{array}{l}\text { Discussion } \\
\text { of all* }\end{array}$ \\
\hline $\begin{array}{l}\text { Alcohol } \\
\text { and } \\
\text { cocaine }\end{array}$ & 13 & $4(8 \%)$ & $4(62 \%)$ & $5(38 \%)$ \\
$\begin{array}{l}\text { Alcohol } \\
\text { and }\end{array}$ & 5 & $2(40 \%)$ & $2(40 \%)$ & $1(20 \%)$ \\
$\begin{array}{l}\text { heroin } \\
\begin{array}{l}\text { Heroin } \\
\text { and }\end{array}\end{array}$ & 16 & $5(31 \%)$ & $5(31 \%)$ & $6(38 \%)$ \\
$\begin{array}{l}\text { cocaine } \\
\text { All three }\end{array}$ & 7 & $1(43 \%)$ & $5(43 \%)$ & $1(14 \%)$ \\
Total & 41 & $29(22 \%)$ & $16(39 \%)$ & $12(29 \%)$ \\
\hline
\end{tabular}

*Includes all instances in which providers were aware of substance use (provider knew prior to visit, unprompted disclosure, disclosure following provider question)
Table 4. Question Types and Examples

\begin{tabular}{|c|c|c|}
\hline$\overline{\text { Question type }}$ & Disclosed & Examples \\
\hline Open-ended $(n=18)$ & $\begin{array}{l}18 \\
(100 \%)\end{array}$ & $\begin{array}{l}\text { - Tell me what's happening with } \\
\text { drugs. } \\
\text { - And in terms of the drug use } \\
\text { how is that going? } \\
\text { - How's the drinking going? }\end{array}$ \\
\hline Normalizing $(n=14)$ & $\begin{array}{l}14 \\
(100 \%)\end{array}$ & $\begin{array}{l}\text { - When was the last time you } \\
\text { used any drugs? } \\
\text { - When was the last time you } \\
\text { used your cocaine? }\end{array}$ \\
\hline $\begin{array}{l}\text { Closed-ended } \\
(n=36)\end{array}$ & $21(58 \%)$ & $\begin{array}{l}\text { - Have you used any coke? } \\
\text { - Are you using any drugs? } \\
\text { - Now are you drinking at all? }\end{array}$ \\
\hline $\begin{array}{l}\text { Leading towards } \\
\text { non-use }(n=9)\end{array}$ & $2(22 \%)$ & $\begin{array}{l}\text { - And you've remained clean } \\
\text { from drugs and alcohol, correct? } \\
\text { - Have you been clean? } \\
\text { - And you haven't been drinking } \\
\text { at all? }\end{array}$ \\
\hline
\end{tabular}

There was a non-significant trend toward increased substance use frequency correlating with higher probabilities of provider questioning and of patient disclosure. There is $3.4 \%$ increased odds of the provider asking about drug use with each additional day of drug use reported on the ASI-lite (OR 1.03, $95 \%$ CI $0.997-1.07$ ) and a $5.1 \%$ increased odds of the patient disclosing accurately with each additional day of drug use reported on the ASI-lite (OR 1.05, $95 \%$ CI 0.99-1.12).

\section{DISCUSSION}

Two main findings emerged from this research. First, when there was an opportunity to elicit disclosure, providers failed to ask about almost half of the reported instances of problematic substance use, and asked about but did not elicit disclosure of an additional 22 instances (14\%). Second, of the four question types identified, open-ended and normalizing questions both elicited disclosure in all cases.

From medical school onward, physicians are advised to use open-ended questions when addressing sensitive topics. Our findings support the efficacy of this approach for eliciting accurate reports of alcohol and drug use in PLWH. We propose that the principle of "question threat," in which survey respondents under-report socially undesirable behaviors, may

Table 5. Unadjusted and Adjusted Risk of Disclosure based on Question Characteristics

\begin{tabular}{cllll}
\hline \hline & Unadjusted & \multicolumn{2}{c}{$\begin{array}{l}\text { Adjusted for type of } \\
\text { drug }\end{array}$} \\
\hline & $\begin{array}{l}\text { Relative } \\
\text { Risk }\end{array}$ & $95 \%$ CI & $\begin{array}{l}\text { Relative } \\
\text { Risk }\end{array}$ & $95 \%$ CI \\
Question type & & & & \\
Open-ended & 1.00 & & 1.00 & \\
Normalizing & 1.00 & & 1.06 & $0.95-$ \\
Closed- & $0.59 * *$ & $0.45-.78$ & $0.60^{* *}$ & 1.17 \\
ended & & & & $0.46-$ \\
Leading & $0.22^{*}$ & $0.06-$ & $0.22^{*}$ & 0.78 \\
& & 0.76 & & $0.06-$ \\
\hline
\end{tabular}

$* p<0.05, * * p<0.001$ 
be applicable in understanding this finding. ${ }^{34}$ Problematic substance use is a sensitive topic with significant surrounding stigma. Open-ended questions may create a sense of less judgment and greater comfort for the patient, reducing response bias. ${ }^{35}$ Yet, it is worth noting that our own work found the opposite when asking about medication adherence: openended questions are associated with lower rates of nonadherence disclosure. ${ }^{36}$ We believe, in the context of antiretroviral adherence, that open-ended questions ("How's it going with the medication?") are not specific enough to elicit nonadherence disclosure, since there are many possible interpretations of the question (e.g. Are there any side effects?, Were you able to obtain the prescription? etc.). However, in the case of substance abuse, open-ended questions are less prone to varied interpretations.

In addition, we found that "normalizing" questions, closedended questions that ask specifically about the "last time" a patient used a substance, also elicited disclosures in all cases. In accordance with the theory of "question threat," we propose that asking about the "last time" normalizes substance use and thus may lower the barrier for disclosure. Secondly, asking about the "last time" may prompt more accurate recall by giving a specific reference-point, increasing disclosure rates. It is important to recognize that the context in which these questions are asked is critical to understanding their normalizing nature. First, all of these encounters were between patients and providers who had established relationships (an inclusion criterion). The likelihood that providers already knew about their past drug use is high in this group, making the question "when is the last time you used?" a reasonable one, rather than a question that makes unfair assumptions.

On the other hand, 'leading' questions that ask whether the patient is "staying clean" or suggest that the patient is "not using" raise the level of question threat and make substance use seem less acceptable. This type of wording may also highlight the stigma attached to substance use, dissuading disclosure for fear of blame or judgment. ${ }^{37}$ Thus, it is not surprising that the 'leading' questions in our sample rarely elicited disclosure.

With regard to poly-substance use, providers elicited full disclosure of all substances in only $29 \%$ of visits. When only some substance use was elicited, cocaine was both asked about and disclosed more frequently than heroin or alcohol. This suggests that providers may be cognizant of the need to ask about cocaine, but stop asking about substance use once they elicit disclosure of cocaine. It is important for providers to ask specifically about other substances when one is disclosed as it is well documented, and also supported in this study, that poly-substance use is common among problematic alcohol and drug users. ${ }^{38-40}$

Previous studies regarding self-reported alcohol and drug use in written or phone surveys have reported mixed findings. Some have found that responses are more accurate when the surveys are "closed-ended," $41-43$ while others suggest that "open-ended" questions elicit more accurate responses to sensitive subjects such as drug and alcohol use. ${ }^{44}$ However, all of these studies use a different definition of open-ended and closed-ended than that used in our study: the difference is whether there are answer choices for the respondent to pick from (closed-ended) or a blank space for the respondent to supply the answer (open-ended). Thus, our findings provide new information regarding verbal clinical interview techniques, the method used by most primary care providers. Our results suggest that open-ended questions are highly valuable when used verbally in the clinical interview, providing higher rates of response than other question types.

Yet, it is also important to note that only half of providers in our sample elicited disclosures of substance use. Future research is needed to determine why providers fail to ask about substance use. Given these low levels of provider questioning, it may be worth considering implementation of a universal screening program to increase patient disclosure rates. For example, using written surveys in the waiting room may lead to greater disclosure without relying on providers to ask about substance use during the clinical encounter.

This study has several limitations. First, it is possible that audio-recording the patient-provider interactions may influence provider or patient behavior. However, we would expect this to lead providers to be more cognizant of their communication styles and content. Additionally, previous studies have found that recording medical interactions has no significant effect on patient or provider behavior. ${ }^{45-47}$ Second, we recognize that these visits are just one interaction in a longitudinal patient-provider relationship and it may be argued that it unreasonable to expect providers to ask about substance use at every visit. However, given that substance use has been extensively shown to decrease antiretroviral adherence and accelerate the clinical course of HIV, we believe that knowledge of active substance use is critically important and merits a prominent spot in the clinical interview. In addition, our sample has a larger percentage of African American and female patients compared to national HIV surveillance data (78 \% vs. $43 \%$ African American nationally, and $42 \%$ vs. $23 \%$ female nationally). ${ }^{48}$ This is likely due to the inclusion criteria of reported substance use (a more prominent etiology of HIV transmission in women than men), as the overall parent study population is more aligned with the national data. Additionally, we hope that our findings will also be informative to general medicine practitioners, and prompt further study of substance use dialogue in non-HIV populations. Finally, this study was observational and there may be unmeasured confounders (e.g., something more functional about the patientprovider relationship that leads to use of a different question type). The sample size is too small to evaluate the potential associations between provider questions and patient and provider race, gender, or other factors.

In summary, it is well documented that problematic substance use is highly prevalent in the population of PLWH and has a negative impact on both medication adherence and disease outcomes. It is therefore critical for providers to be 
aware of substance use so as to be able to counsel and guide patients to appropriate treatment. In this study, almost half of providers failed to discuss substance use with patients who were using cocaine, heroin, or engaging in heavy alcohol use. Providers can increase the probability of accurate patient disclosure by asking open-ended, broad questions or by asking closed-ended questions that inquire about the "last time" that a patient used drugs or alcohol.

Acknowledgements: This research was supported by a contract from the Health Resources Service Administration and the Agency for Healthcare Research and Quality (AHRQ 290-01-0012). In addition, Dr. Korthuis was supported by the National Institute of Drug Abuse (K23 DA019809). Dr. Saha was supported by the Department of Veterans Affairs, and Dr. Beach was supported by the National Institute of Drug Abuse (K24 DA037804). None of the funders had a role in the design and conduct of this analysis, nor was it subject to their final approval. None of the authors have any relevant financial conflicts of interest.

Corresponding Author: Wynne Callon, BA; Johns Hopkins University School of Medicine, 2024 East Monument Street, Baltimore, MD 21205, USA (e-mail: wcallon1@jhmi.edu).

\section{Compliance with Ethical Standards:}

Conflicts of Interest: The authors declare that they do not have a conflict of interest.

\section{REFERENCES}

1. Beckett MK, Collins RL, Burnam MA, Kanouse DE, Bing EG, Longshore DL, et al. Mental Health and Substance Abuse Issues Among People with HIV [Internet]. 2007 [accessed 2016 Apr 10]. Available from: http://www. rand.org/pubs/research_briefs/RB9300.html.

2. Nath A, Hauser KF, Wojna V, Booze RM, Maragos W, Prendergast M, et al. Molecular basis for interactions of HIV and drugs of abuse. J Acquir Immune Defic Syndr 1999. 2002;31(Suppl 2):S62-9.

3. Chander G, Lau B, Moore RD.Hazardous alcohol use: a risk factor for non-adherence and lack of suppression in HIV infection. J Acquir Immune Defic Syndr 1999. 2006;43(4):411-7.

4. Miguez MJ, Shor-Posner G, Morales G, Rodriguez A, Burbano X. HIV treatment in drug abusers: impact of alcohol use. Addict Biol. 2003;8(1):33-7.

5. Lucas GM, Gebo KA, Chaisson RE, Moore RD. Longitudinal assessment of the effects of drug and alcohol abuse on HIV-1 treatment outcomes in an urban clinic. AIDS Lond Engl. 2002;16(5):767-74.

6. Chander G, Himelhoch S, Moore RD. Substance abuse and psychiatric disorders in HIV-positive patients: epidemiology and impact on antiretroviral therapy. Drugs. 2006;66(6):769-89.

7. Lucas GM, Griswold M, Gebo KA, Keruly J, Chaisson RE, Moore RD. Illicit drug use and HIV-1 disease progression: a longitudinal study in the era of highly active antiretroviral therapy. Am J Epidemiol. 2006;163(5):412-20.

8. Cohn SE, Jiang H, McCutchan JA, Koletar SL, Murphy RL, Robertson KR, et al. Association of ongoing drug and alcohol use with non-adherence to antiretroviral therapy and higher risk of AIDS and death: results from ACTG 362. AIDS Care. 2011;23(6):775-85.

9. Cofrancesco J, Scherzer R, Tien PC, Gibert CL, Southwell H, Sidney S, et al. Illicit drug use and HIV treatment outcomes in a US cohort. AIDS Lond Engl. 2008;22(3):357-65.

10. Hinkin CH, Barclay TR, Castellon SA, Levine AJ, Durvasula RS, Marion SD, et al. Drug Use and Medication Adherence among HIV-1 Infected Individuals. AIDS Behav. 2006;11(2):185-94.

11. Hendershot CS, Stoner SA, Pantalone DW, Simoni JM. Alcohol use and antiretroviral adherence: review and meta-analysis. J Acquir Immune Defic Syndr 1999. 2009;52(2): 180.

12. Samet JH, Horton NJ, Meli S, Freedberg KA, Palepu A. Alcohol consumption and antiretroviral adherence among HIV-infected persons with alcohol problems. Alcohol Clin Exp Res. 2004;28(4):572-7.
13. Arnsten JH, Demas PA, Grant RW, Gourevitch MN, Farzadegan H, Howard AA, et al. Impact of active drug use on antiretroviral therapy adherence and viral suppression in HIV-infected drug users. J Gen Intern Med. 2002;17(5):377-81.

14. Rosen MI, Black AC, Arnsten JH, Goggin K, Remien RH, Simoni JM, et al. Association between use of specific drugs and antiretroviral adherence: findings from MACH 14. AIDS Behav. 2013;17(1):142-7.

15. Bing EG, Burnam M, Longshore D, et al. Psychiatric disorders and drug use among human immunodeficiency virus-infected adults in the United States. Arch Gen Psychiatry. 2001;58(8):721-8.

16. TJ Cory PR. New Antiretroviral Therapies and Potential Drug Interactions in HIV Infected Drug Abusers. J Antivir Antiretrovir. 2014;06(03).

17. Kumar S, Rao P, Earla R, Kumar A. Drug-drug interactions between antiretroviral therapies and drugs of abuse in HIV systems. Expert Opin Drug Metab Toxicol. 2014;11(3):343-55.

18. Friedmann PD, McCullough D, Saitz R. Screening and intervention for illicit drug abuse: a national survey of primary care physicians and psychiatrists. Arch Intern Med. 2001;161(2):248-51.

19. Hawkins EJ, Kivlahan DR, Williams EC, Wright SM, Craig T, Bradley KA. Examining quality issues in alcohol misuse screening. Subst Abuse. 2007;28(3):53-65.

20. Moriarty HJ, Stubbe MH, Chen L, Tester RM, Macdonald LM, Dowell AC, et al. Challenges to alcohol and other drug discussions in the general practice consultation. Fam Pract. 2012;29(2):213-22.

21. Korthuis PT, Josephs JS, Fleishman JA, Hellinger J, Himelhoch S, Chander G, et al. Substance abuse treatment in human immunodeficiency virus: the role of patient-provider discussions. J Subst Abuse Treat. 2008;35(3):294-303.

22. McCormick KA, Cochran NE, Back AL, Merrill JO, Williams EC, Bradley KA. How primary care providers talk to patients about alcohol: a qualitative study. J Gen Intern Med. 2006;21(9):966-72.

23. Beach MC, Saha S, Korthuis PT, Sharp V, Cohn J, Wilson IB, et al. Patient-provider communication differs for black compared to white HIVinfected patients. AIDS Behav. 2011;15(4):805-11.

24. Beach MC, Saha S, Korthuis PT, Sharp V, Cohn J, Wilson I, et al. Differences in patient-provider communication for Hispanic compared to non-Hispanic white patients in HIV care. J Gen Intern Med. 2010;25(7):682-7.

25. Beach MC, Roter D, Korthuis PT, Epstein RM, Sharp V, Ratanawongsa $\mathbf{N}$, et al. A multicenter study of physician mindfulness and health care quality. Ann Fam Med. 2013;11(5):421-8.

26. Saha S, Korthuis PT, Cohn JA, Sharp VL, Moore RD, Beach MC. Primary care provider cultural competence and racial disparities in HIV care and outcomes. J Gen Intern Med. 2013;28(5):622-9.

27. Korthuis PT, Saha S, Chander G, McCarty D, Moore RD, Cohn JA, et al. Substance use and the quality of patient-provider communication in HIV clinics. AIDS Behav. 2011;15(4):832-41.

28. Beach MC, Roter DL, Saha S, Korthuis PT, Eggly S, Cohn J, et al. Impact of a brief patient and provider intervention to improve the quality of communication about medication adherence among HIV patients. Patient Educ Couns. 2015;98(9):1078-83.

29. McLellan AT, Luborsky L, Woody GE, O'Brien CP. An improved diagnostic evaluation instrument for substance abuse patients. The Addiction Severity Index. J Nerv Ment Dis. 1980;168(1):26-33.

30. Cacciola JS, Alterman AI, McLellan AT, Lin Y-T, Lynch KG. Initial evidence for the reliability and validity of a "Lite" version of the Addiction Severity Index. Drug Alcohol Depend. 2007;87(2-3):297-302.

31. Saunders JB, Aasland OG, Babor TF, de la Fuente JR, Grant M. Development of the Alcohol Use Disorders Identification Test (AUDIT): WHO Collaborative Project on Early Detection of Persons with Harmful Alcohol Consumption-II. Addict Abingdon Engl. 1993;88(6):791-804.

32. Peräkylä A. Conversation analysis: a new model of research in doctorpatient communication. J R Soc Med. 1997;90(4):205-8.

33. Drew P, Chatwin J, Collins S. Conversation analysis: a method for research into interactions between patients and health-care professionals. Health Expect Int $\mathrm{J}$ Public Particip Health Care Health Policy. 2001;4(1):58-70.

34. Bradburn NM, Sudman S, Blair E, Stocking C. Question threat and response bias. Public Opin Q. 1978;42(2):221-34.

35. Ray MK, Beach MC, Nicolaidis C, Choi D, Saha S, Korthuis PT. Patient and provider comfort discussing substance use. Fam Med. 2013;45(2):109-17.

36. Callon W, Saha S, Korthuis PT, Wilson IB, Moore RD, Cohn J, et al. Which Clinician Questions Elicit Accurate Disclosure of Antiretroviral Nonadherence When Talking to Patients? AIDS Behav. 2015 Oct 26;1-8. 
37. Kelly JF, Wakeman SE, Saitz R. Stop talking "dirty": clinicians, language, and quality of care for the leading cause of preventable death in the United States. Am J Med. 2015;128(1):8-9.

38. Staines GL, Magura S, Foote J, Deluca A, Kosanke N. Polysubstance use among alcoholics. J Addict Dis. 2001;20(4):53-69.

39. Leri F, Bruneau J, Stewart J. Understanding polydrug use: review of heroin and cocaine co-use. Addiction. 2003;98(1):7-22.

40. Conway KP, Kane RJ, Ball SA, Poling JC, Rounsaville BJ. Personality, substance of choice, and polysubstance involvement among substance dependent patients. Drug Alcohol Depend. 2003;71(1):65-75.

41. Ekholm O, Strandberg-Larsen K, Christensen K, Grønbaek M. Comparison of assessment methods for self-reported alcohol consumption in health interview surveys. Eur J Clin Nutr. 2008;62(2):286-91.

42. Gmel G, Lokosha O. Self-reported frequency of drinking assessed with a closed- or open-ended question format: a split-sample study in Switzerland. J Stud Alcohol. 2000;61(3):450-4.

43. Ivis FJ, Bondy SJ, Adlaf EM. The effect of question structure on selfreports of heavy drinking: closed-ended versus open-ended questions. J Stud Alcohol. 1997;58(6):622-4.
44. Blair E, Sudman S, Bradburn NM, Stocking C. How to Ask Questions about Drinking and Sex: Response Effects in Measuring Consumer Behavior. J Mark Res. 1977;14(3):316-21.

45. Wolraich ML, Albanese M, Stone G, Nesbitt D, Thomson E, Shymansky J, et al. Medical Communication Behavior System. An interactional analysis system for medical interactions. Med Care. 1986;24(10):891-903.

46. Pringle M, Stewart-Evans C. Does awareness of being video recorded affect doctors' consultation behaviour? Br J Gen Pract. 1990;40(340):4558.

47. Penner LA, Orom H, Albrecht TL, Franks MM, Foster TS, Ruckdeschel JC. Camera-related behaviors during video recorded medical interactions. J Nonverbal Behav. 2007;31(2):99-117.

48. CDC. Diagnoses of HIV infection and AIDS in the United States and dependent areas, 2014 [Internet]. Atlanta, GA: US Department of Health and Human Services, CDC; 2015 [cited 2016 Mar 8]. (HIV surveillance report). Report No.: vol. 21. Available from: http://www.cdc.gov/hiv/ library/reports/surveillance/. 